\title{
FÓRUM
}

Submetido 10.01.2014. Aprovado 27.06.2014

Avaliado pelo processo de double blind review. Editores Científicos: Gleen Morgan e Maria José Tonelli

DOI: http://dx.doi.org/10.1590/So034-759020150302

\section{TEORIA INSTITUCIONAL E MODOS DE ENTRADA DE MULTINACIONAIS DE PAIISES EMERGENTES}

\author{
Institutional theory and entry modes by emerging markets multinationals \\ Teoría institucional y modos de ingreso de multinacionales de países \\ emergentes
}

\begin{abstract}
RESUMO
Este ensaio teórico busca analisar os espaços de contribuição da perspectiva institucional de análise para o entendimento das escolhas de modo de entrada de empresas multinacionais provenientes de países emergentes. Modos de entrada referem-se às decisões de grau de controle da subsidiária (subsidiária integral versus joint venture). Alguns autores propõem que o modo de entrada seria influenciado pelas três dimensões do ambiente institucional: distância regulatória, normativa e cultural-cognitiva entre o país hospedeiro e o país de origem da empresa investidora. A partir de ampla revisão bibliográfica, são identificados fatores relacionados aos três pilares do ambiente institucional e formuladas proposições para orientar estudos empíricos futuros sobre modos de entrada de multinacionais de países emergentes.
\end{abstract}

PALAVRAS-CHAVE | Institucionalismo, modos de entrada, multinacionais, distância institucional, países emergentes.

\begin{abstract}
This essay aims at contributing to the analysis of the spaces for contribution of the institutional perspective of analysis to advance the understanding of entry mode choices by multinational firms from emerging markets. Entry modes refer to the decisions involving the degree of control of a subsidiary (wholly-owned versus joint venture). Some authors propose that three dimensions of the institutional environment influence the entry mode decision: regulative distance, normative distance and cultural-cognitive distance between the host country and the country of origin of the investing firm. Starting from a broad review of the extant literature, this study identifies factors related to the three pillars of the institutional environment and advances propositions to be tested in future studies on entry mode choices of emerging market multinationals.
\end{abstract}

KEYWORDS / Institutionalism, entry modes, multinationals, institutional distance, emerging countries.

\section{ANGELA DA ROCHA}

amc.darocha@gmail.com

Professora da Pontifícia

Universidade Católica do Rio de

Janeiro, Escola de Negócios - Rio de

Janeiro - RJ, Brasil

\section{HENRIQUE DE AZEVEDO ÁVILA}

henavila@uol.com.br

Doutor em Administração pela

Universidade Federal do Rio de

Janeiro, Instituto Coppead de

Administração - Rio de Janeiro - RJ, Brasil

\section{RESUMEN}

Ese ensayo teórico busca analizar los espacios de contribución de la perspectiva institucional de análisis para el entendimiento de las elecciones del modo de ingreso de empresas multinacionales provenientes de países emergentes. Modos de ingreso se refieren a las decisiones de grado de control de la subsidiaria (subsidiaria integral versus joint venture). Algunos autores proponen que el modo de ingreso sería influenciado por las tres dimensiones del ambiente institucional: distancia regulatoria, normativa y cultural-cognitiva entre el país hospitalario y el país de origen de la empresa inversora. A partir de amplia revisión bibliográfica, son identificados factores relacionados a los tres pilares del ambiente institucional y formuladas proposiciones para orientar estudios empíricos futuros sobre modos de ingreso de multinacionales de países emergentes.

PALABRAS-CLAVE I Institucionalismo, modos de entrada, multinacionales, distancia institucional, países emergentes. 


\section{INTRODUÇÃO}

0 recente movimento de internacionalização de empresas de países emergentes, associado ao crescimento dos países onde essas companhias estão sediadas, tem despertado o interesse dos estudiosos de negócios internacionais para a escassez de estudos sobre o tema (Khanna \& Palepu, 2006; Luo \& Tung, 2007). Além disso, os autores divergem quanto a se as características dos processos de internacionalização das multinacionais de países emergentes (EMNEs, do inglês Emerging Market Multinational Enterprises) se assemelham ou não àquelas de multinacionais de países desenvolvidos (Ramamurti, 2012; Rugman, 2009). Nos últimos anos, a teoria institucional tem se tornado uma alternativa importante para o entendimento das decisões de investimento das multinacionais, em especial as oriundas de países emergentes, uma vez que busca capturar aspectos fundamentais do país de origem e do país de destino dos investimentos realizados (Peng, Wang, \& Jiang, 2008), não enfatizados pelas demais teorias. Para Dunning e Lundan (2008), a teoria institucional oferece um caminho promissor para o avanço do entendimento sobre as diferentes formas das multinacionais contemporâneas.

Três principais abordagens ao institucionalismo estão hoje presentes nos estudos de negócios internacionais: nova economia institucional, novo institucionalismo organizacional e institucionalismo histórico comparado. Entre essas, as duas primeiras concentram os estudos que têm buscado medir a distância institucional entre países e, portanto, são as abordagens consideradas no presente estudo.

A expressão "nova economia institucional" foi criada por Williamson em 1975, para expressar um conjunto de conceitos que expandiriam o horizonte da teoria neoclássica acerca dos fenômenos econômicos. A nova economia institucional tem o seu foco na interação entre as instituições e as firmas resultantes das imperfeições de mercado (Hoskisson, Eden, Lau, \& Wright, 2000) e está fortemente atrelada ao pensamento microeconômico. Os novos institucionalistas reconhecem a importância das forças de mercado para o desenvolvimento econômico, mas defendem que as instituições sejam posicionadas como elemento central. Tal abordagem permitiria explorar melhor as implicações das imperfeições de mercado no comportamento dos atores econômicos. 0 emprego da economia institucional para se entender o papel das instituições ganhou força a partir dos trabalhos de North $(1990,1991)$ e Williamson (2000), principais expoentes do novo institucionalismo econômico. Esses trabalhos incorporaram conceitos provenientes de teorias antecessoras, como os de custos de transação e de racionalidade limitada, ainda que North focalize as "regras do jogo" no ambiente econômico e Williamson trate mais diretamente da governança institucional, examinando o funcionamento interno da firma. A nova economia institucional advoga que as instituições trazem três importantes contribuições para o bom funcionamento dos mercados: i) reduzem os custos de transação, ao melhorar a qualidade das informações e diminuir sua assimetria; ii) protegem os direitos de propriedade; iii) balizam o ambiente de competição, ao impor regras (Dumludag, Saridogan, \& Kurt, 2007).

O novo institucionalismo organizacional está ancorado na sociologia e na teoria organizacional, e tem sua ênfase nas formas e práticas organizacionais. Trata-se de uma abordagem contemporânea das organizações em que se desenvolve uma visão sociológica das instituições e do modo como essas instituições afetam a sociedade. Para os novos institucionalistas organizacionais, há não só instituições formais, mas também sistemas normativos e culturais-cognitivos, que seriam as instituições informais. 0 presente trabalho adota como recorte teórico a classificação de pilares institucionais proposta por Scott (2001, p. 48): “instituições são compostas por elementos regulatórios, normativos e culturais-cognitivos, que, juntos com atividades e recursos associados, conferem estabilidade e sentido à vida social". 0 pilar regulatório compreenderia as leis e regras vigentes, o pilar normativo envolveria as normas e valores seguidos por seus habitantes e o pilar cultural-cognitivo corresponderia à forma como os indivíduos inferem e interpretam os estímulos do ambiente.

A teoria institucional vem sendo utilizada em estudos de negócios institucionais já há alguns anos, cobrindo diversos aspectos do campo. 0 presente estudo trata especificamente do uso da teoria institucional na decisão de modos de entrada de EMNEs em mercados externos. 0 modo de entrada, ou seja, a escolha da forma de propriedade das subsidiárias no exterior (de subsidiária integral a joint venture minoritária), é uma das principais decisões que a firma investidora toma, ao entrar em um mercado estrangeiro. No caso das EMNEs, as decisões de modo de entrada parecem sofrer forte influência do ambiente institucional, tanto do país de origem dos investimentos quanto do país receptor. A maior parte dos estudos utiliza-se predominantemente da abordagem econômica, ou seja, da nova economia institucional, com ênfase, sobretudo, na teoria de custos de transação (Barkema \& Vermeulen, 1998; Dikova \& Witteloostuijn, 2007; Gorynia \& Mroczek, 2013; Luo, 2001), sendo ainda poucos os estudos que utilizam a perspectiva adotada no presente trabalho, baseada nos três pilares institucionais de Scott (1995, 2001).

Não obstante, é importante frisar que outros caminhos potenciais se colocam aos pesquisadores no âmbito da teoria institucional, como retratam, por exemplo, os trabalhos de Child e 
Tsai (2005) e Child e Rodrigues (2005). Além disso, cabe mencionar explicitamente que já existem alguns trabalhos realizados no Brasil que utilizam a abordagem institucional associada a modos de entrada. Salientam-se, em particular, os trabalhos de Amal e associados (Amal \& Kegel, 2012; Amal, Raboch, \& Tomio, 2009), de cunho econômico, mais voltados para a análise dos efeitos atrelados à qualidade do ambiente institucional e a políticas públicas. Por sua vez, Sepúlveda (2012) e Chueke e Borini (2012) tratam especificamente do modo de estabelecimento de subsidiárias no exterior (aquisição versus greenfield).

$\mathrm{Na}$ análise do impacto do ambiente institucional sobre as decisões de negócios internacionais, os estudos focam dois aspectos distintos: o impacto do ambiente institucional do país de origem sobre as decisões de modo de entrada e o impacto do ambiente institucional do país hospedeiro sobre essas decisões. 0 foco do presente trabalho está relacionado especificamente ao impacto do ambiente institucional do país hospedeiro sobre as decisões de modo de entrada das EMNEs, enfatizando, portanto, a relação entre elementos do ambiente institucional e escolhas organizacionais.

Este ensaio ampara-se nos três pilares institucionais propostos por Scott para propor relações entre o ambiente institucional dos países receptores de investimentos diretos e o modo de entrada escolhido pela EMNE. A contribuição do trabalho reside em dois aspectos. 0 primeiro consiste na própria identificação das variáveis relevantes ao entendimento do impacto dos fatores do ambiente institucional sobre a decisão de modos de entrada, com base em ampla revisão dos diversos estudos na literatura. O segundo decorre do desenvolvimento de um conjunto de proposições, incorporando especificidades esperadas nas escolhas de modos de entrada por EMNEs.

Para seleção dos estudos mencionados neste trabalho, foi realizada uma ampla revisão da literatura relevante sobre modos de entrada em mercados externos, cobrindo o período de 1990 a 2012. Inicialmente foram pesquisados os periódicos reconhecidos na área de Negócios Internacionais: International Business Review, International Marketing Review, Journal of International Business Studies, Journal of International Management, Journal of International Marketing, Journal of World Business e Management International Review. Foram também pesquisados periódicos de caráter geral na área de Administração, mas que publicam frequentemente artigos da área de $\mathrm{Ne}$ gócios Internacionais: Academy of Management Journal, Academy of Management Review, Journal of Business Research, Journal of Management, Journal of Management Studies e Strategic Management Journal. Uma vez identificados os artigos que tratavam de modos de entrada em mercados externos, foi realizada uma leitura do abstract para separar aqueles que eram es- tudos empíricos e que tratavam especificamente da decisão entre joint ventures e subsidiárias integrais, objeto do presente trabalho. Além disso, buscaram-se artigos adicionais utilizando diversas bases de dados nacionais e internacionais. Utilizaram-se também artigos seminais sobre o tema específico.

0 artigo está estruturado da seguinte forma: após esta introdução, em que são apresentados o contexto, a delimitação do estudo e seu posicionamento, discute-se o impacto de fatores institucionais sobre os modos de entrada. Em seguida, são detalhados, para cada um dos pilares institucionais de Scott, quais os fatores identificados na literatura que se encontram associados àquele pilar, as proposições concernentes à relação de cada fator com a decisão de modo de entrada e uma proposta de operacionalização dos fatores identificados. Finalmente, são feitas as considerações finais do trabalho.

\section{IMPACTO DE FATORES INSTITUCIONAIS SOBRE O MODO DE ENTRADA}

Nem sempre a escolha de modo de entrada pode ser tomada livremente pela empresa, já que muitos governos impedem a participação majoritária de capital estrangeiro em indústrias consideradas estratégicas (Slangen \& Tulder, 2009; Xu \& Shenkar, 2002). Quando a empresa tem liberdade para decidir o nível de propriedade desejado, variáveis do ambiente institucional do país hospedeiro podem afetar essa decisão, levando a escolha a pender para subsidiárias integrais ou para joint ventures. Segue-se indicação apenas parcial de estudos, dadas as limitações de espaço.

Um conceito fundamental para o entendimento da questão é o de distância institucional, referente a diferenças entre o ambiente institucional do país de origem e o do país hospedeiro. A noção de distância institucional foi desenvolvida e refinada por Kostova $(1997,1999)$, autora expoente do novo institucionalismo organizacional, tendo sido aplicada com frequência aos estudos de negócios internacionais (Busenitz, Gómez, \& Spencer, 2000). Quando a firma multinacional se defronta com um ambiente institucional muito diferente do seu país de origem, tem dificuldade para se estabelecer e manter sua legitimidade (Kostova \& Zaheer, 1999), bem como para transferir suas práticas para a subsidiária que vier a ser ali instalada (Kostova, 1999; Kostova \& Roth, 2002).

De maneira geral, os estudos mostram que relacionam distância institucional a modos de entrada mostram que maior distância institucional levaria à formação de joint ventures, enquanto menor distância institucional favoreceria o estabelecimento de subsidiárias integrais. Por exemplo, Yiu e Makino 
(2002) encontraram evidências do impacto dos três pilares institucionais sobre a escolha de modo de entrada de multinacionais japonesas: o arcabouço regulatório do país hospedeiro, as pressões normativas impostas pela comunidade local e as limitações decorrentes de dissonância entre os padrões de referência cognitivos da multinacional e os de eventuais parceiros no país receptor, levando à preferência por joint ventures em países com grande distância regulatória e normativa. Xu, Pan e Beamish (2004) também verificaram a associação das distâncias regulatória e normativa com menores níveis de participação no capital da afiliada.

A revisão dos estudos que associam aspectos do ambiente institucional à escolha do modo de entrada de empresas multinacionais sugere a existência de lacunas no entendimento da questão. Salientam-se a seguir aquelas que têm chamado a atenção dos estudiosos do tema:

1. Não há consenso, ainda, quanto ao que constitui o ambiente institucional no estudo de negócios internacionais. Brouthers (2013) sugere que é fundamental se chegar a um acordo sobre o âmbito conceitual do construto, para, só então, discutir as medidas operacionais adequadas.

2. A maioria dos artigos tende a privilegiar aspectos regulatórios e normativos, sem cobrir os três pilares propostos por Scott (1995).

3. Não ficam claros os critérios que têm balizado a seleção dos fatores estudados, dando a impressão de escolha idiossincrática de cada autor (Bae \& Salomon, 2010).

Uma questão sobre a qual parece haver consenso é a de que importa mais a diferença entre o padrão das instituições dos países de origem e de destino do que o nível absoluto de qualidade das instituições do país hospedeiro. Ou seja, as firmas se disporiam a adotar modos de entrada que representassem maior comprometimento quando o ambiente institucional do país receptor fosse semelhante ao ambiente de seus países de origem (Xu \& Shenkar, 2002). Isso significa que a distância, por si só, traria ônus para o investidor, independentemente de o ambiente institucional do país hospedeiro ser mais ou menos favorável a investimentos estrangeiros.

Cabe chamar a atenção para o fato de alguns autores haverem detectado efeitos de interação entre os três pilares institucionais de Scott. Por exemplo, Eden e Miller (2004) registraram que, na prática, os diferentes tipos de distância institucional se combinam, formando construtos de maior complexidade. Os autores examinaram o conceito de distância institucional sob dois diferentes prismas: um relativo a diferenças culturais (decomposto em elementos normativos e culturais-cognitivos) e outro relativo à corrupção (decomposto em elementos regulatórios e normativos).

\section{FATORES DO AMBIENTE INSTITUCIONAL NOS PAIISES HOSPEDEIROS E PROPOSIÇÕES TEÓRICAS}

O primeiro passo consistiu em identificar, na literatura, um conjunto de variáveis que expressassem adequadamente os diferentes fatores que compõem cada um dos três pilares do ambiente institucional, ou seja, identificar o domínio conceitual dos construtos distância regulativa, distância normativa e distância cultural-cognitiva. Em seguida, foram formuladas proposições, apoiadas na literatura, correspondentes à relação entre cada um dos fatores identificados e o modo de entrada da firma no mercado externo (subsidiárias integrais versus joint ventures). Por fim, para cada um dos pilares, são apresentadas formas de operacionalizar os fatores extraídos da literatura.

\section{Pilar institucional regulatório}

O pilar institucional regulatório compreende regras e regulamentos estabelecidos por lei ou referendados pela opinião pública, que têm o poder de encorajar certos comportamentos e desencorajar outros. Os mecanismos coercitivos que governam o pilar institucional regulatório são normalmente impostos por entidades investidas de mandato para cobrar seu cumprimento. Dois aspectos do ambiente institucional regulatório são levados em conta: de um lado, quais são as "regras do jogo"; de outro (e sobretudo), a sua efetiva e consistente aplicação (enforcement).

Em função disso, os ambientes institucionais regulatórios dos países podem ser classificados como de maior ou menor qualidade. Em contextos de maior qualidade regulatória, há respeito aos direitos e liberdades civis e às leis e regulamentos, sendo aplicados, quando necessário, mecanismos coercitivos e de controle para garantir o cumprimento das leis e regulamentos e a proteção dos direitos de indivíduos e organizações. Em ambientes de menor qualidade regulatória, o governo pode intervir intempestivamente nos negócios, a força da lei não é consistente e eficientemente imposta, e os mecanismos de controle e enforcement não são confiáveis.

Identificou-se, na literatura, fatores associados ao pilar institucional regulatório, que são apresentados no Quadro 1. Os autores referenciados no quadro utilizaram esses fatores em seus respectivos estudos, embora não necessariamente todos eles encontrem-se afiliados a alguma das abordagens do institucionalismo. Além disso, devido a limitações de espaço, não foi possível referenciar todos os autores identificados, citando-se apenas os mais representativos. 


\section{Quadro 1. Fatores do pilar regulatório}

\begin{tabular}{|c|c|c|c|}
\hline $\begin{array}{l}\text { Fatores do país } \\
\text { hospedeiro }\end{array}$ & Descrição & Exemplos de estudos empíricos & $\begin{array}{l}\text { Exemplos de variáveis usadas para } \\
\text { medir o fator }\end{array}$ \\
\hline $\begin{array}{l}\text { Nível de intervenção } \\
\text { do governo }\end{array}$ & $\begin{array}{l}\text { Capacidade do governo para formu- } \\
\text { lar e implementar políticas e normas } \\
\text { que interfiram no setor privado }\end{array}$ & $\begin{array}{l}\text { Arslan e Larimo (2010); Brouthers } \\
\text { (2002); Delios e Beamish (1999); } \\
\text { Dikova e Witteloostuijn (2007); Estrin } \\
\text { et al. (2009); Gaur e Lu (2007) }\end{array}$ & $\begin{array}{l}\text { Consistência e transparência das po- } \\
\text { líticas governamentais }\end{array}$ \\
\hline $\begin{array}{l}\text { Qualidade do } \\
\text { arcabouço jurídico }\end{array}$ & $\begin{array}{l}\text { Qualidade do arcabouço jurídico do } \\
\text { país, facilitando a criação e gestão } \\
\text { de negócios por firmas estrangeiras }\end{array}$ & $\begin{array}{l}\text { Estrin et al. (2009); Roy e Oliver } \\
\text { (2009); Xu et al. (2004) }\end{array}$ & $\begin{array}{l}\text { Existência de mecanismos de prote- } \\
\text { ção a contratos, complexidade da le- } \\
\text { gislação trabalhista, facilidade para } \\
\text { expatriação de empregados }\end{array}$ \\
\hline $\begin{array}{l}\text { Proteção a direitos } \\
\text { de propriedade }\end{array}$ & $\begin{array}{l}\text { Instrumentos que asseguram ao pro- } \\
\text { prietário de um ativo o poder discri- } \\
\text { cionário de utilizá-lo e usufruir dos } \\
\text { retornos por ele propiciados }\end{array}$ & $\begin{array}{l}\text { Arslan e Larimo (2010); Delios e } \\
\text { Beamish, 1999; Luo (2001); Dikova } \\
\text { e Witteloostuijn (2007); Gaur et al. } \\
\text { (2007); Gaur e Lu (2007); Meyer, Es- } \\
\text { trin, Bhaumik e Peng (2009); Pajunen } \\
\text { (2008) }\end{array}$ & $\begin{array}{l}\text { Adequação de leis de proteção a di- } \\
\text { reitos de propriedade, simplicidade } \\
\text { dos procedimentos de proteção a } \\
\text { direitos de propriedade }\end{array}$ \\
\hline
\end{tabular}

Observe-se que, entre os fatores identificados, os dois primeiros referem-se à ação governamental (nível de intervenção e grau de protecionismo), os dois seguintes, às regras do jogo econômico (restrição ao investimento estrangeiro e proteção a direitos de propriedade) e os dois últimos, à proteção jurídica (qualidade das leis e capacidade de assegurar seu cumprimento).

A procura de legitimidade em ambientes institucionais de baixa qualidade regulatória é difícil, porque é complicado atender às exigências regulatórias específicas existentes em cada país. Em tais ambientes, ter um parceiro local permite acesso a conhecimentos sobre as leis e regulamentos do país de destino, e assim mitigar a desvantagem do estrangeiro (Zaheer, 1995). Paralelamente, ambientes mais restritivos são frequentemente caracterizados por instabilidade política, o que também convida à associação com parceiros locais, que já possuem expertise em lidar com essas dificuldades. A opção por joint ventures pode proporcionar ainda maior capacitação de processamento de informação do que, por exemplo, parcerias ou alianças contratuais.

As evidências são múltiplas, por exemplo: alto grau de intervenção do governo nos negócios e baixo nível de proteção aos direitos de propriedade levariam à preferência por joint ventures (Luo, 2001); a falta de proteção a direitos de propriedade desestimularia a formação de parcerias com sócios locais, dado o risco de esses parceiros se comportarem de maneira oportunista (Eden \& Miller, 2004); e restrições de natureza legal e barreiras comerciais (Morschett, Schramm-Klein, \& Swoboda, 2010) estimulariam a formação de joint ventures.

Observe-se que os resultados citados anteriormente emanam de trabalhos que, em sua quase totalidade, estudaram multinacionais de países desenvolvidos. Assim, encontra-se razoavelmente estabelecido na literatura que multinacionais de países desenvolvidos preferem entrar por meio de joint ventures em am- 
bientes institucionais de baixa qualidade regulatória, que são aqueles que apresentam maior distância regulativa em relação ao ambiente institucional de seus países de origem.

No entanto, há discussão quanto a como esses fatores interferem no caso de multinacionais provenientes de países emergentes (EMNEs). Alega-se, por um lado, que as firmas oriundas das economias emergentes estão mais familiarizadas com instituições regulatórias mais restritivas, uma vez que essas firmas tiveram que lidar com deficiências e carência de proteção regulatória em seus países de origem. Na realidade, essa familiaridade e a habilidade de lidar e tirar proveito de lacunas institucionais constituiria um peculiar e importante ativo das firmas emergentes que proporcionaria vantagens competitivas em relação a multinacionais provenientes de países de origem desenvolvidos (Khanna \& Palepu, 2006). Por outro lado, é de se esperar que as EMNEs não façam restrições a investir em países de alta qualidade regulatória, simplesmente por se originarem de países com baixa qualidade regulatória. Assim, quando se considera a distância regulatória, pode-se supor que as decisões das EMNEs quanto ao modo de entrada (de subsidiária integral a joint venture minoritária) não sejam diretamente afetadas pela distância regulativa dos países de origem aos países de destino.

As seguintes proposições são apresentadas, indicando a relação esperada entre a escolha do modo de entrada e a qualidade do ambiente regulatório:

P1a. Diferenças no grau de intervenção do governo no país hospedeiro em relação a seu país de origem não afetam a probabilidade de a EMNE escolher joint ventures ou subsidiárias integrais como modo de entrada.

P1b. Diferenças no grau de protecionismo no país hospedeiro em relação a seu país de origem não afetam a probabilidade de a EMNE escolher joint ventures ou subsidiárias integrais como modo de entrada.

P1c. Diferenças nas restrições ao investimento estrangeiro no país hospedeiro em relação a seu país de origem não afetam a probabilidade de a EMNE escolher joint ventures ou subsidiárias integrais como modo de entrada.

P1d. Diferenças na proteção aos direitos de propriedade no país hospedeiro em relação a seu país de origem não afetam a probabilidade de a EMNE escolher joint ventures ou subsidiárias integrais como modo de entrada.

P1e. Diferenças na qualidade do arcabouço jurídico no país hospedeiro em relação a seu país de origem não afetam a probabilidade de a EMNE escolher joint ventures ou subsidiárias integrais como modo de entrada.
P1f. Diferenças na qualidade do sistema judiciário do país hospedeiro em relação a seu país de origem não afetam a probabilidade de a EMNE escolher joint ventures ou subsidiárias integrais como modo de entrada.

Não se excluem, no entanto, interações entre fatores associados a diferentes pilares institucionais. É possível que a distância cultural-cognitiva atue como mediadora nas relações propostas (de P1a a P1f). Por exemplo, em países hospedeiros de alta distância cultural-cognitiva em relação ao país de origem da EMNE, é possível que prevaleçam joint ventures, não apenas devido às diferenças culturais mas também devido às diferenças regulatórias. Isso ocorreria pelo fato de não ser possível transferir o conhecimento experiencial de como lidar com esses fatores a países hospedeiros com grandes diferenças culturais. Outras interações, inclusive entre fatores do mesmo pilar, podem ser hipotetizadas. Por exemplo, diferenças entre o tipo de sistema jurídico dominante no país de origem no país hospedeiro - ordenamentos jurídicos embasados no direito romano, na common law, ou no direito muçulmano - poderiam afetar a decisão de modo de entrada.

Incluem-se também, no Quadro 1, exemplos de variáveis utilizadas para medir cada fator. Essas variáveis podem ser utilizadas como variáveis perceptuais (usando-se escalas tipo Likert), buscando verificar como os executivos veem a distância entre o país de origem da empresa e o país hospedeiro dos investimentos. Podem-se, ainda, usar diversos índices já existentes, compilados por organizações de prestígio internacional. Por exemplo, há os indicadores do Global Competitiveness Index, do Fórum Econômico Mundial, os índices do World Competitiveness Yearbook, do IMD, e o Economic Freedom Index, da Heritage Foundation. $\mathrm{O}$ uso desses índices é bastante difundido na literatura, como nos estudos de Xu et al. (2004) e Estrin, Baghdasaryan e Meyer (2009).

\section{Pilar institucional normativo}

O pilar institucional normativo compreende valores e normas que definem os tipos de comportamento considerados desejáveis, apropriados e corretos, como condição necessária à validação de papéis sociais (Scott, 1995, 2001). Valores e normas indicam a indivíduos e organizações os padrões sob os quais seu comportamento será avaliado. Assim, o pilar institucional normativo pode ser traduzido na forma da cultura nacional de determinado país, uma vez que reflete hipóteses, sistemas de valores, normas e crenças sobre o comportamento humano, compartilhados e comumente aceitos por determinada sociedade. Diferentemente do pilar regulatório, a adequação não é o resultado de pressões coercitivas, uma vez que o princípio da 
adequação são a aceitação e a conformidade com as normas e valores, sendo uma obrigação moral. As pressões oriundas desse componente são chamadas de pressões normativas.

Além de valores e crenças, a corrupção e a burocracia são incluídas no presente estudo como parte do pilar institucional normativo, embora não haja consenso na literatura quanto a se esses fatores devem ser tratados como parte do pilar regulatório ou do normativo. No entanto, o presente trabalho se apoia nas orientações de Scott $(1995,2001)$ de que o comportamento organizacional normativo pode ser definido como o modo rotineiro como as pessoas fazem as coisas e que determinadas características institucionais podem impregnar, ao longo do tempo, o contexto normativo, ao passarem a integrar a mentalidade vigente. Isso ocorreria com a corrupção, cujo problema é sua onipresença, a que se alia sua imprevisibilidade (Rodriguez, Uhlenbruck, \& Eden, 2005). Da mesma forma, trata-se aqui o fenômeno da burocracia como conceito organizacional, prevalecendo as noções de mentalidade e comportamento burocrático (Scott \& Pandey, 2000).

Também com relação ao pilar institucional normativo, foram identificados fatores associados a esse construto (Quadro 2) e referenciados autores relevantes. Além disso, são apresentadas algumas variáveis que compõem cada fator, identificadas na literatura, sem a ambição de ser exaustivo.

\section{Quadro 2. Fatores do pilar normativo}

\begin{tabular}{|c|c|c|c|}
\hline $\begin{array}{l}\text { Fatores do país } \\
\text { hospedeiro }\end{array}$ & Descrição & Exemplos de estudos empíricos & $\begin{array}{l}\text { Exemplos de variáveis usadas para } \\
\text { medir o fator }\end{array}$ \\
\hline Valores & $\begin{array}{l}\text { Fundamentos de natureza moral que } \\
\text { orientam o comportamento da socie- } \\
\text { dade na condução de negócios }\end{array}$ & $\begin{array}{l}\text { Barkema e Vermeulen (1998); Estrin et } \\
\text { al. (2009); Kogut e Singh (1988); Peng } \\
\text { (2003); Yiu e Makino (2002) }\end{array}$ & $\begin{array}{l}\text { Importância atribuída a lazer e entre- } \\
\text { tenimento, valorização da segurança } \\
\text { na vida pessoal e profissional, valori- } \\
\text { zação do sucesso profissional }\end{array}$ \\
\hline Crenças & $\begin{array}{l}\text { Convicções da sociedade local acerca } \\
\text { do que é "verdadeiro" }\end{array}$ & $\begin{array}{l}\text { Barkema e Vermeulen (1998); Estrin et } \\
\text { al. (2009); Kogut e Singh (1988); Peng } \\
\text { (2003); Yiu e Makino (2002) }\end{array}$ & $\begin{array}{l}\text { Crença na superioridade das decisões } \\
\text { individuais sobre as coletivas, respei- } \\
\text { to à autoridade. }\end{array}$ \\
\hline $\begin{array}{l}\text { Relações de } \\
\text { confiança }\end{array}$ & $\begin{array}{l}\text { Facilidade para a construção de con- } \\
\text { fiança e grau de influência dos rela- } \\
\text { cionamentos nos negócios }\end{array}$ & $\begin{array}{l}\text { Delios e Beamish (1999); Eden e Miller } \\
\text { (2004); Jansson, Hilmersson e San- } \\
\text { dberg (2011); Meyer (2001); Tsui-Auch } \\
\text { e Möllering (2010) }\end{array}$ & $\begin{array}{l}\text { Importância da construção de con- } \\
\text { fiança no ambiente profissional, im- } \\
\text { portância de relações de confiança } \\
\text { com clientes }\end{array}$ \\
\hline Corrupção & $\begin{array}{l}\text { Intensidade da corrupção no sistema } \\
\text { político }\end{array}$ & $\begin{array}{l}\text { Demirbag, McGuinness e Altay (2010); } \\
\text { Estrin, Baghdasaryan e Meyer (2009); } \\
\text { Gaur, Delios e Singh (2007); Jansson, } \\
\text { Hilmersson e Sandberg (2011); Ro- } \\
\text { driguez, Uhlenbruck e Eden (2005); } \\
\text { Uhlenbruck e outros (2006) }\end{array}$ & $\begin{array}{l}\text { Onipresença da corrupção, imprevisi- } \\
\text { bilidade da corrupção }\end{array}$ \\
\hline $\begin{array}{l}\text { Mentalidade } \\
\text { burocrática }\end{array}$ & $\begin{array}{l}\text { Rigidez na aplicação de regras e pro- } \\
\text { cedimentos administrativos desne- } \\
\text { cessários }\end{array}$ & $\begin{array}{l}\text { Agarwal e Feils (2007); Demirbag, } \\
\text { Tatoglu e Glaister (2008); Gaur et al. } \\
\text { (2007); Gaur e Lu (2007) }\end{array}$ & $\begin{array}{l}\text { Existência de entraves burocráticos } \\
\text { em diferentes níveis da administra- } \\
\text { ção, aplicação de mais regras, ou } \\
\text { aplicação excessiva de regras por } \\
\text { funcionários responsáveis por proce- } \\
\text { dimentos burocráticos }\end{array}$ \\
\hline
\end{tabular}


De modo geral, no tocante à distância normativa, Eden e Miller (2004) mostraram que a constituição de joint ventures ocorria dada a dificuldade em manter o alinhamento com as práticas da matriz, entender as orientações emanadas do ambiente institucional e conquistar legitimidade. No entanto, grande distância institucional normativa levou empresas finlandesas a preferirem instalar subsidiárias integrais (Arslan \& Larimo, 2010), contrariando as hipóteses iniciais levantadas no estudo.

A presença da corrupção como parte do contexto institucional normativo tem sido objeto de diversos estudos específicos no campo dos negócios internacionais, criando-se inclusive a expressão “distância em termos de corrupção" (Duanmu, 2011). Para Rodriguez et al. (2005) e Uhlenbruck. Rodriguez, Doh, e Eden (2006), quanto mais alta a corrupção no país hospedeiro, maior será a probabilidade de a firma investidora preferir modos de entrada com menor participação de capital próprio. Por outro lado, o modo de entrada adotado em países com alto índice de corrupção dependeria do próprio nível de corrupção do país de origem (Duanmu, 2011).

Seguindo o mesmo raciocínio desenvolvido com relação ao pilar regulatório, argumenta-se que, as EMNEs, em geral provenientes de países com altos índices de corrupção e burocracia, tenderiam a se sentir mais à vontade em ambientes institucionais com níveis de corrupção e burocracia similares do que as multinacionais provenientes de países com baixos níveis de corrupção. Não obstante, as EMNEs não deixariam de considerar também atraentes ambientes em que os níveis de corrupção e a prevalência da mentalidade burocrática fossem baixos, dado que esses dois fatores aumentam os custos de fazer negócios. Em síntese, esse raciocínio levou à formulação das proposições P2d e P2e de maneira distinta das demais proposições relativas ao pilar normativo. Seguem-se as proposições que expressam a relação entre esses fatores e a escolha de modo de entrada pela EMNE.

P2a. Quanto mais distintos os valores dominantes no país hospedeiro em relação aos valores que prevalecem no país de origem, maior a probabilidade de a EMNE escolher joint ventures como modo de entrada, em vez de subsidiárias integrais.

P2b. Quanto mais distintas as crenças dominantes no país hospedeiro em relação às crenças que prevalecem no país de origem, maior a probabilidade de a EMNE escolher joint ventures como modo de entrada, em vez de subsidiárias integrais.

P2c. Quanto mais distinto o papel dos relacionamentos na realização de negócios no país hospedeiro em relação ao que se verifica no país de origem, maior a probabilidade de a EMNE escolher joint ventures como modo de entrada, em vez de subsidiárias integrais.
P2d. Diferenças no nível de corrupção existente para a realização de negócios no país hospedeiro, em relação a seu país de origem, não afetam a probabilidade de a EMNE escolher joint ventures ou subsidiárias integrais como modo de entrada.

P2e. Diferenças no grau de mentalidade burocrática dominante no país hospedeiro, em relação a seu país de origem, não afetam a probabilidade de a EMNE escolher joint ventures ou subsidiárias integrais como modo de entrada.

Da mesma forma como ocorre com relação ao ambiente institucional regulatório, as formas de medir o pilar normativo podem passar pelo uso de medidas perceptuais, normalmente obtidas por meio de survey com os decisores, ou por meio de índices já existentes, como é o caso do Corruption Perceptions Index (CPI) e o Bribe Payers Index, ambos divulgados pela Transparência Internacional. Outros índices utilizados para medir o pilar normativo provêm da World Values Survey, conduzida pela The World Values Survey Association (WVSA).

\section{Pilar institucional cultural-cognitivo}

Esse pilar refere-se à maneira pela qual os indivíduos percebem e interpretam a realidade. No pilar cultural-cognitivo, a ação é entendida como uma interpretação subjetiva. Assim, para entender as instituições, deve-se levar em conta não só as condições objetivas da vida social mas também a sua interpretação subjetiva pelos atores (Scott, 1995, 2001). Scott (2001, p. 57) salienta que "a atenção com a dimensão cultural-cognitiva das instituições é a principal característica distintiva do neoinstitucionalismo dentro da sociologia e do estudo das organizações".

Na literatura em geral, reconhece-se que há substancial interseção teórica entre os pilares normativo e cultural-cognitivo (Gaur, Delios, \& Singh, 2007; Gaur \& Lu, 2007; Peng, 2009). 0 próprio Scott (2001) reconheceu que a fronteira entre os pilares normativo e cognitivo não é completamente clara. Não obstante, o primeiro refletiria como os valores, crenças e atitudes de terceiros podem influenciar o comportamento da firma em questão; o segundo corresponderia ao impacto dos valores e crenças da própria firma (Peng, 2009). Para Eden e Miller (2004), o pilar normativo define o que as pessoas "devem ou não devem fazer" e o pilar cultural-cognitivo, por sua vez, corresponde ao que "é ou não é verdade" e ao que "se tem ou não capacidade para fazer”. Para Meyer e Rowan (1977), o pilar cultural-cognitivo reconhece o fato de que a cultura de uma sociedade é determinante na forma como os seus membros percebem e reagem às instituições que os cercam. 
Com base na literatura examinada, foram identificados fatores associados a esse construto (Quadro 3) e respectivos estudos. Além disso, são apresentadas algumas variáveis que compõem cada fator identificado na literatura.

Quadro 3. Fatores do pilar cultural-cognitivo

\begin{tabular}{l|l|l|l}
\hline $\begin{array}{l}\text { Fatores do país } \\
\text { hospedeiro }\end{array}$ & Descrição & Exemplos de estudos empíricos & $\begin{array}{l}\text { Exemplos de variáveis usadas para } \\
\text { medir o fator }\end{array}$ \\
\hline Estereótipos & $\begin{array}{l}\text { Percepção desfavorável acerca do in- } \\
\text { vestidor externo, em função de seu } \\
\text { país de origem }\end{array}$ & $\begin{array}{l}\text { Chattalas, Kramer e Takada (2008); } \\
\text { Zaheer (1999) }\end{array}$ & $\begin{array}{l}\text { Preconceito contra profissionais es- } \\
\text { trangeiros em função do seu país de } \\
\text { origem, preferência dos compradores } \\
\text { pelos bens ou serviços produzidos } \\
\text { em seu próprio país }\end{array}$ \\
\hline Práticas gerenciais & $\begin{array}{l}\text { Posturas, atitudes e procedimentos } \\
\text { de gestão }\end{array}$ & $\begin{array}{l}\text { Busenitz et al. (2000); Estrin et al. } \\
\text { (2009); Ferreira, Li e Suk (2009) }\end{array}$ & $\begin{array}{l}\text { Prioridade conferida a metas finan- } \\
\text { ceiras ou resultados de curto prazo, } \\
\text { novas tecnologias e processos, cen- } \\
\text { tralização das decisões nos níveis } \\
\text { hierárquicos superiores }\end{array}$ \\
\hline Identidades & $\begin{array}{l}\text { Aspectos socioculturais do país hos- } \\
\text { pedeiro }\end{array}$ & $\begin{array}{l}\text { Arslan e Larimo (2010); Dow e Larimo } \\
\text { (2009); Makino e Tsang (2011) }\end{array}$ & $\begin{array}{l}\text { Idioma, raízes coloniais, nível de edu- } \\
\text { cação da população }\end{array}$ \\
\hline
\end{tabular}

A noção de distância ou diferenças entre os países tem sido objeto de diversos estudos, porém o conceito mais utilizado até hoje ainda é o de distância cultural. Foi a partir do trabalho de Kogut e Singh (1988) que o construto de distância cultural passou a ser mais frequentemente utilizado em estudos sobre modo de entrada. Brouthers e Brouthers (2001) apontam divergências na literatura que trata da relação entre distância cultural e modo de entrada: alguns pesquisadores constataram que altos níveis de distância cultural estão associados à opção por subsidiárias integrais ou joint ventures majoritárias; outros encontraram associação direta com joint ventures. De um lado, defende-se que a parceria com um sócio local facilitaria a adaptação dos produtos e a realização de atividades sensíveis à cultura do país hospedeiro. Em contraposição, há argumentos na direção contrária, uma vez que a distância cultural dificultaria a identificação de um parceiro adequado e a gestão da afiliada no exterior.

Harzing (2004) analisou 13 estudos sobre o impacto da distância cultural na escolha entre subsidiárias integrais e joint ventures, verificando a existência de proposições teóricas e resultados estatísticos conflitantes: sete encontraram relacionamento positivo entre distância cultural e controle compartilhado, três acharam relacionamento negativo, um concluiu que o relacionamento segue uma trajetória curvilínea e os outros dois não obtiveram suporte estatístico para as hipóteses. Vale registrar ainda que as metanálises realizadas por Tihanyi, Griffith e Russell (2005) e Morschett et al. (2010) também não encon- traram evidências para o relacionamento direto entre distância cultural e a seleção do modo de entrada.

Em termos de distância cultural-cognitiva, Eden e Miller (2004) observaram que a análise do seu impacto na escolha do modo de entrada deve ser vista de maneira mais ampla, uma vez que há diferentes aspectos do comportamento das firmas e dos consumidores do país receptor que podem interferir na decisão da empresa investidora.

Seguem-se as proposições que expressam a relação entre esses fatores e a escolha de modo de entrada pela EMNE, construídas a partir da literatura. De modo geral, não há expectativas de diferenças entre o comportamento das EMNEs e das multinacionais tradicionais com relação a esse pilar.

P3a. Quanto mais desfavorável a imagem do país de origem da EMNE no país hospedeiro, maior a probabilidade de a EMNE escolher joint ventures como modo de entrada, em vez de subsidiárias integrais.

P3b. Quanto mais distintas as práticas gerenciais do país hospedeiro em relação às do país de origem, maior a probabilidade de a EMNE escolher joint ventures como modo de entrada, em vez de subsidiárias integrais.

P3c. Quanto mais distinta a identidade nacional do país hospedeiro em relação à do país de origem, maior a probabilidade de a EMNE escolher joint ventures como modo de entrada, em vez de subsidiárias integrais. 
Para medir a distância cultural-cognitiva, é frequente o uso das dimensões culturais de Hofstede (1980), operacionalizadas por Kogut e Singh (1988). Em menor escala, utilizam-se também os resultados do Projeto Globe (Global Leadership and Organizational Behavior Effectiveness), coordenado por House, Hanges, Javidan, Dorfman e Gupta (2004), a World Values Survey e os trabalhos de Schwartz (por exemplo, López-Duarte \& Vidal-Suárez, 2012).

\section{CONSIDERAÇÕES FINAIS}

Pesquisadores de diferentes correntes teóricas têm se dedicado a avaliar a influência das instituições dos países de origem e destino nas decisões de investimento das multinacionais. Experiências de multinacionais de países emergentes já levaram à proposta de que os aspectos institucionais passem a ter um papel proeminente, somando-se às perspectivas baseadas na indústria e nos recursos da firma, para explicar as estratégias seguidas pelas companhias em seus negócios internacionais (Peng et al. 2008). Com esse papel proeminente, haveria uma mudança no status dos fatores pertinentes ao ambiente institucional, equiparando-os a fatores já validados na literatura.

No entanto, ainda não está claro se as variáveis do ambiente institucional afetariam de modo similar as EMNEs, comparativamente às multinacionais de países desenvolvidos. Nesse contexto, as proposições apresentadas no presente trabalho têm o propósito de contribuir para o conhecimento existente acerca da influência do ambiente institucional sobre as escoIhas de modos de entrada (subsidiária integral versus joint venture) por empresas multinacionais, particularmente aquelas originárias de economias emergentes.

Alguns aspectos adicionais devem ser considerados. As proposições avançadas no presente estudo partem do pressuposto de que os decisores das EMNEs representam o ambiente institucional de seu país de origem, o que nem sempre é verdadeiro. Embora a própria ideia de cultura pressuponha compartilhamento, não se pode deixar de considerar a existência de subculturas das quais podem provir os decisores. Além disso, executivos de multinacionais podem ser oriundos de outros países. Embora isso ainda seja incomum entre as multinacionais brasileiras, é de se esperar a presença de profissionais estrangeiros na direção de subsidiárias, particularmente à medida que se amplia o fenômeno de internacionalização de empresas brasileiras. Outra questão que deve merecer a atenção dos pesquisadores, levantada neste estudo, refere-se a possíveis interações entre os pilares institucionais, que devem ser cuidadosamente consideradas em futuras pesquisas.

\section{Nota da Redação}

Este artigo foi apresentado no $8^{\text {th }}$ Iberoamerican Academy Conference - World in Transition: business, multiculturalism and society em dezembro de 2013, promovido pela Fundação Getulio Vargas/ Escola de Administração de Empresas de São Paulo (FGV/ EAESP).

\section{REFERÊNCIAS}

Agarwal, J., \& Feils, D. (2007). Political risk and the internationalization of firms: an empirical study of Canadian-based export and FDI firms. Canadian Journal of Administrative Sciences, 24(3), 165-181.

Amal, M., \& Kegel, P. L. (2012). Determinants of Brazilian outward foreign direct investment: a home country perspective. In M. Marinov, \& S. Marinova (Org.). Impacts of emerging economies and firms on international business (p. 168-188). London, U.K.: Palgrave Macmillan.

Amal, M, Raboch, H., \& Tomio, B. T. (2009). Strategies and determinants of foreign direct investment (FDI) from developing countries: case study of Latin America. Latin American Business Review, 10(2-3), 73-94.

Arslan, A., \& Larimo, J. (2010). Ownership strategy of multinational enterprises and the impacts of regulative and normative institutional distance: evidence from Finnish foreign direct investments in Central and Eastern Europe. Journal of East - West Business, 16(3), 179-200.

Bae, J-H., \& Salomon, R. (2010). Institutional distance and international business research. In T. M. Devinney, T. Pedersen, \& L. Tihanyi (Coord.). The past, present and future of international business and management. advances in international management (Vol. 23, p. 327-349). New York, NY: Emerald.

Barkema, H. G., \& Vermeulen, F. (1998). International expansion through start-up or acquisition: a learning perspective. Academy of Management Journal, 41(1), 7-26.

Brouthers, K. D. (2002). Institutional, cultural and transaction cost influences on entry mode choice and performance. Journal of International Business Studies, 33(2), 203-221.

Brouthers, K. D. (2013). A retrospective on: institutional, cultural and transaction cost influences on entry mode choice and performance. Journal of International Business Studies, 44(1), 14-22.

Brouthers, K. D., \& Brouthers, L. E. (2001). Explaining the national cultural distance paradox. Journal of International Business Studies, 32(1), 177-189.

Busenitz, L. W, Gómez, C., \& Spencer, J. W. (2000). Country institutional profiles: unlocking entrepreneurial phenomena. Academy of Management Journal, 43(5), 994-1003.

Chattalas, M, Kramer, T., \& Takada, H. (2008). The impact of national stereotypes on the country of origin effect: a conceptual framework. International Marketing Review, 25(1), 54-74. 
Child, J., \& Rodrigues, S. B. (2005). The internationalization of Chinese firms: a case for theoretical extension? Management and Organization Review, 1(3), 381-410.

Child, J., \& Tsai, T. (2005). The dynamic between firms' environmental strategies and institutional constraints in emerging economies: evidence from China and Taiwan. Journal of Management Studies, $42(1)$, 95-125.

Chueke, G. V., \& Borini, F. M. (2012). Distância institucional e estratégia de entrada das multinacionais brasileiras no exterior. Anais do Encontro da ANPAD, Rio de Janeiro, 36.

Delios, A., \& Beamish, P. W. (1999). Ownership strategy of Japanese firms: transactional, institutional and experience influences. Strategic Management Journal, 20(10), 915-933.

Demirbag, M, McGuinness, M., \& Altay, H. (2010). Perceptions of institutional environment and entry mode: FDI from an emerging country. Management International Review, 50(2), 207-240.

Demirbag, M., Tatoglu, E., \& Glaister, K.W. (2008). Factors affecting perceptions of the choice between acquisition and greenfield entry: the case of Western FDI in an emerging market. Management International Review, 48(1), 5-38.

Dikova, D., \& Witteloostuijn, A. van. (2007). Foreign direct investment mode choice: entry and establishment modes in transition economies. Journal of International Business Studies, 38(6), 1013-1033.

Dow, D., \& Larimo, J. (2009). Challenging the conceptualization and measurement of distance and international experience in entry mode choice research. Journal of International Marketing, 17(2), 74-98.

Duanmu, J-L. (2011). The effect of corruption distance and market orientation on the ownership choice of MNEs: evidence from China. Journal of International Management, 17(2), 162-174.

Dumludag, D. (2009). An analysis of the determinants of foreign direct investment in Turkey: the role of the institutional context. Journal of Business Economics and Management, 10(1), 15-30.

Dumludag, D. (2010). The quality of institutions and multinational corporation: the political economy of foreign direct investment in Turkey. In T. Cetin, \& F. Yilmaz (Org.) Understanding the process of institutional change in Turkey: a political economy approach. Nova Science Publishers: New York.

Dumludag, D, Saridogan, E., \& Kurt, S. (2007). Determinants of foreign direct investment: an institutionalist approach. Proceedings of the Conference of the European Historical Economics Society, Lund, Sweden, 7.

Dunning, J. H., \& Lundan, S. M. (2008). Institutions and the OLI paradigm of the multinational enterprise. Asia Pacific Journal of Management, 25(4), 573-593.

Eden, L., \& Miller, S. R. (2004). Distance matters: liability of foreignness, institutional distance and ownership strategy. In M. Hitt, \& J. Cheng (Eds.). Theories of the multinational enterprise: diversity, complexity and relevance. (Vol. 16, p. 187-221). (Advances in International Management). New York, NY: Emerald.

Estrin, S, Baghdasaryan, D., \& Meyer, K. E. (2009). The impact of institutional and human resource distance on international entry strategies. Journal of Management Studies, 46(7), 1171-1196.
Ferreira, M. P, Li, D., \& Suk J. Y. (2009). Foreign entry strategies: strategic adaptation to the various facets of the institutional environments. Development and Society, 38(1), 27-55.

Gaur, A. S, Delios, A., \& Singh, K. (2007). Institutional environments, staffing strategies, and subsidiary performance. Journal of Management, 33(4), 611-636.

Gaur, A. S, \& Lu, J. W. (2007). Ownership strategies and survival of foreign subsidiaries: impacts of institutional distance and experience. Journal of Management, 33(1), 84-110.

Gorynia, M, \& Mroczek, K. (2013). Institutional context and transaction costs in entry mode choice. Journal of Economics \& Management, 14, 51-59.

Harzing, A-W. (2004). The role of culture in entry-mode studies: from neglect to myopia? In J. L. C. Cheng, \& M. A. Hitt (Org.). Managing multinationals in a knowledge economy: economics, culture, and human resources. (Vol. 15, p. 75-127). (Advances in International Management). New York, NY: Emerald.

Hofstede, G. (1980). Culture's consequences: international differences in work-related values. Beverly Hills, CA: Sage Publications.

Hoskisson, R. E, Eden, L, Lau, C. M., \& Wright, M. (2000). Strategies in emerging economies. Academy of Management Journal, 43(3), 249-267.

House, R. J, Hanges, P. J, Javidan, M, Dorfman, P. W., \& Gupta, V. (Org.). (2004). Culure, leadership and organizations: The Globe study of 62 countries. Thousand Oaks, C.A.: Sage.

Jansson, H, Hilmersson, M., \& Sandberg, S. (2011). Perceived institutional distance in the emerging market entry process. International Journal of Business Environment, 4(3), 268-286.

Khanna, T., \& Palepu, K. G. (2006). Emerging giants: building worldclass companies in developing countries. Harvard Business Review, 84(10), 60-69.

Kogut, B., \& Singh, H. (1988). The effect of national culture on the choice of entry mode. Journal of International Business Studies, 19(3), 411-432.

Kostova, T. (1997). Country institutional profiles: concept and measurement. Academy of Management Best Paper Proceedings, 1(Supplement), 180-184.

Kostova, T. (1999). Transnational transfer of strategic organizational practices: a contextual perspective. The Academy of Management Review, 24(2), 308-324.

Kostova, T., \& Roth, K. (2002). Adoption of an organizational practice by subsidiaries of multinational corporations: institutional and relational effects. Academy of Management Journal, 45(1), 215-233.

Kostova, T., \& Zaheer, S. (1999). Organizational legitimacy under conditions of complexity: the case of the multinational enterprise. Academy of Management Review, 24(1), 64-81.

López-Duarte, C., \& Vidal-Suaréz, M.M. (2012). Cultural distance and the choice between wholly owned subsidiaries and joint ventures. Journal of Business Research, 66(11), 2252-2261.

Luo, Y. (2001). Determinants of entry in an emerging economy: a multilevel approach. Journal of Management Studies, 38(3), 443-472.

Luo, Y., \& Tung, R. (2007). International expansion of emerging market enterprises: a springboard perspective. Journal of International Business Studies, 38(4), 481-498.

Makino, S., \& Tsang, E. W. K. (2011). Historical ties and foreign direct investment: an exploratory study. Journal of International Business Studies, 42(4), 545-557. 
Meyer, J. W., \& Rowan, B. (1977). Institutionalized organizations: formal structure as myth and ceremony. American Journal of Sociology, 83(2), 340-363.

Meyer, K. E. (2001). Institutions, transaction costs, and entry mode choice in Eastern Europe. Journal of International Business Studies, 32(2), 357-367.

Meyer, K. E, Estrin, S, Bhaumik, S. K., \& Peng, M. W. (2009). Institutions, resources, and entry strategies in emerging economies. Strategic Management Journal, 30(1), 61-80.

Morschett, D, Schramm-Klein, H., \& Swoboda, B. (2010). Decades of research on market entry modes: what do we really know about external antecedents of entry mode choice? Journal of International Management, 16(1), 60-77.

North, D. C. (1990). Institutions, institutional change and economic performance. New York: Cambridge University Press.

North, D. C. (1991). Institutions. The Journal of Economic Perspectives, 5(1), 97-112.

Pajunen, K. (2008). Institutions and inflows of foreign direct investment: a fuzzy-set analysis. Journal of International Business Studies, 39(4), 652-669.

Peng, M. W. (2003). Institutional transitions and strategic choices. Academy of Management Review, 28(2), 275-296.

Peng, M. W. (2009). Global business. Cincinnati, OH: South-Western Cengage Learning.

Peng, M. W, Wang, D. Y. L., \& Jiang, Y. (2008). An institution-based view of international business strategy: a focus on emerging economies. Journal of International Business, 39(5), 920-936.

Ramamurti, R. (2012). What is really different about emerging market multinationals? Global Strategy Journal, 2(1), 41-47.

Rodriguez, P, Uhlenbruck, K., \& Eden, L. (2005). Government corruption and the entry strategies of multinationals. Academy of Management Review, 30(2), 383-396.

Roy, J-P., \& Oliver, C. (2009). International joint venture partner selection: the role of the host-country legal environment. Journal of International Business Studies, 40(5), 779-801.

Rugman, A. (2009). Theoretical aspects of MNEs from emerging countries. In R. Ramamurti, \& J. Singh (Org.). Emerging multinationals in emerging markets. Cambridge, U.K: Cambridge University Press.
Scott, W. R. (1995). Institutions and organizations: ideas and interests. Thousand Oaks: Sage.

Scott, W. R. (2001). Institutions and organizations: ideas and interests. (2nd ed.). Thousand Oaks: Sage.

Scott, P. G., \& Pandey, S. K. (2000). The influence of red tape on bureaucratic behavior: an experimental simulation. Journal of Policy Analysis and Management, 19(4), 615-633.

Sepúlveda, M. P. V. (2012). Estratégia de entrada de multinacionais brasileiras em países estrangeiros. Dissertação de mestrado, Insper Instituto de Ensino e Pesquisa, São Paulo.

Slangen, A. H. L., \& Tulder, R. J. M. van. (2009). Cultural distance, political risk, or governance quality? Towards a more accurate conceptualization and measurement of external uncertainty in foreign entry mode research. International Business Review, 18(3), 276-291.

Tihanyi, L, Griffith, D., \& Russell, C. J. (2005). The effect of cultural distance on entry mode choice, international diversification, and MNE performance: a meta-analysis. Journal of International Business Studies, 36(3), 270-283.

Tsui-Auch, L. S., \& Möllering, G. (2010). Wary managers: unfavorable environments, perceived vulnerability, and the development of trust in foreign enterprises in China. Journal of International Business Studies, 41(6), 1016-1035.

Uhlenbruck, K, Rodriguez, P, Doh, J., \& Eden, L. (2006). The impact of corruption on entry strategy: evidence from telecommunication projects in emerging economies. Organization Science, 17(3), 402-414.

Williamson, O. E. (2000). The new institutional economics: taking stock, looking ahead. Journal of Economic Literature, 38(3), 595-613.

Xu, D, Pan, Y., \& Beamish, P. W. (2004). The effect of regulative and normative distances on MNE ownership and expatriate strategies. Management International Review, 44(3), 285-307.

Xu, D., \& Shenkar, O. (2002). Institutional distance and the multinational enterprise. Academy of Management Review, 27(4), 608-618.

Yiu, D., \& Makino, S. (2002). The choice between joint venture and wholly owned subsidiary: an institutional perspective. Organization Science, 13(6), 667-683.

Zaheer, S. (1995). Overcoming the liability of foreignness. Academy of Management Journal, 38(2), 341-3 